\title{
EN NOSOTROS VIVE EL MOVIMIENTO PEDAGÓGICO*
}

Hablar de Movimiento Pedagógico es rescatar nuestra vida como educadores, es permitimos reflexionar sobre los temas fundamentales de nuestra praxis, es preguntamos si realmente estamos en el cambio, o, repitiendo el esquema tradicional que siempre criticamos.

Hablar de Movimiento Pedagógico es tener en cuenta los 70 años que al interior del grupo de trabajo, suman nuestras prácticas como maestros y 100 años como estudiantes, esto es, 170 años de intervención educativa, casi dos siglos; experiencias suficientes como materia prima para una historia de la pedagogía.

Cuando niños deseamos entrar a la escuela, la vivimos, la padecimos, gozamos con ella y hoy podemos decir que somos profesionales, "productos" formados por la educación. Como maestros, nos sentimos plenamente comprometidos a contribuir con los hechos que permitan la realización de una nueva historia.

Historia que parte de la vida cotidiana de la escuela, del hacer y deshacer, de la reacción a lo formalista, de la inquietud por el conocimiento y la rabia consciente del peso de la ignorancia; de las inconsecuencias entre el decir y el hacer, de los inventos soñados, de la imaginación para trasladar una práctica política revolucionaria, a una práctica pedagógica y llevar la pedagogía al seno de la revolución.

Hoy en otro momento, esta revolución tiene como sustento la participación, la democracia, la convivencia, el respeto al otro y la lucha por la vida, como las condiciones para construir el nuevo proyecto pedagógico.

La construcción de este proyecto, es movimiento social, político, intelectual; esto es, acción social, lucha de la inteligencia, integración de la comunidad, reflexión colectiva y compromiso personal. Es movimiento de una praxis para meterse en todos los vericuetos populares e intelectuales, es ser igual al estudiante, aprender su lenguaje, comprender su ritmo, es organizar aquí y allá, es trabajar por encontrar sentido a una labor, que como la educación, centra todo el interés de la sociedad.

Retomamos para el nuevo proyecto pedagógico, la lucha por el maestro y su compromiso con el estudiante, con el pueblo y con el país y su reconocimiento como trabajador de la cultura y agente del cambio social, que de planteamientos de hace 15 años, se llega a realizaciones que ahora nos tienen concertando planes de desarrollo, elaborando proyectos educativos institucionales, investigando y además, estudiando un postgrado de pedagogía en educación física, que realmente demuestra que el objeto del saber del maestro, se centra en el saber de la pedagogía.

La pedagogía tiene un compromiso político con la defensa de la educación pública, frente al proceso de privatización; de la construcción de un concepto de calidad, más allá de la eficacia y la productividad; de una administración moderna, pero no limitada a la eficiencia burocrática; de la descentralización con participación; de la financiación con inversión dentro de un verdadero sentido social; de la concertación de las políticas educativas, sin la anulación de las iniciativas de la comunidad.

\footnotetext{
* Protocolo elaborado por Clara L. Peña, Julia C. Peña, Víctor Chinchilla, Miguel Molano y Jesús Álvarez, presentado en la asignatura Problemática general de la Educación del Postgrado de Pedagogía y Didáctica en Educación Física.
} 
La pedagogía supera la transmisión del conocimiento-como objeto de la escuela, para centrarse en procesos de construcción, en los que la investigación hace parte de la cotidianidad en el descubrimiento de la ciencia, en la expresión artística, en la composición de movimientos, en el rescate de la cultura autóctona, en la formación de los valores para un nuevo ciudadano, en la ampliación de las fronteras de la escuela hacia el saber de la comunidad y de una nueva didáctica, centrada en el aprender a aprender.

\section{Elementos que propicia un nuevo proyecto pedagógico:}

Se asume que el movimiento pedagógico se construye en nuestra vida cotidiana de maestros, en la cual exista consecuencia entre decir y el hacer. Los elementos de un nuevo proyecto pedagógico se centran en puntos sencillos de esta cotidianidad:

\section{Aprender a ser maestro:}

El trabajo del maestro es un recorrido permanente hacia el conocimiento, como apropiación personal con responsabilidad social, esto es, las consecuencias de mi conocimiento, o ignorancia, no me afectan sólo a mi, sino ante todo, al otro. Por ello es más propio hablar de construcción, no de transmisión del conocimiento; a ello hay un compartir entre mi trabajo con el otro, pero tal responsabilidad me compromete aún más. ¿Cómo aprender a asumir este reto?

Debo asumir que soy un estudiante permanente, que la complejidad de mi tarea, me obligaa a un esfuerzo constante de lucha contra el facilismo y los dogmas de someter a la crítica colectiva mi práctica, en un concepto real de comunidad académica, es decir aprendo a ser maestro con el otro y con los otros.

\section{Tomar en serio nuestra labor:}

la complejidad dela labor docente, lleva al hecho de que toda palabra y todo acto del maestro, tienen una implicación educativa, lo que reafirma la idea, que ser maestro es todo un estilo de vida. No se trata de una obsesión por ser un ejemplo permanente, sino estructurar una personalidad que define su identidad, en la coherencia entre el decir y el hacer, no asumido como una tortuosa actividad, sino como un trabajo que se asume con la misma seriedad con la que juega el niño (Moore, P).

\section{Darle significado a la vida escolar:}

La escuela no debe plantearse como expectativa de futuro, sino como una realidad presente, "no se trata de educar para la vida, sino entender que la escuela es la vida misma" (Vasco), con todo su valor para cl individuo y la sociedad. Esto es permitir un desarrollo personal pleno y hacer de cada escuela, un centro de aprendizaje del proyecto de país que queremos.

\section{Ampliarlas fronteras de la escuela:}

La dinámica pedagógica planteada, requiere una nueva institución escolar (ya prevista por la ley), que permita la participación comunitaria, reconozca los conocimientos y prácticas extraescolares, dimensione la importancia de la institución escolar en la comunidad y 
asimile críticamente las influencias de medios tan poderosos como la televisión y otras formas de comunicación y publicidad.

Eso implica una nueva comprensión y reorganización del tiempo y su aprendizaje, porque puede pensarse, que el niño está en la escuela, aun estando en su casa.

Es también la apropiación que hace la escuela de la cultura y de los medios presentes en el entorno, para dimensionarlos pedagógicamente e influir en ellos.

\section{La velocidad del cambio:}

Decir que lo escrito anteriormente, mañana es transformado, es mostrar que la escuela, al contrario de los tiempos pasados, debe fijar su acción en la capacidad de promover o aceptar cambios, tanto en el ámbito del conocimiento como en la interacción social y el aprendizaje de normas para las nuevas situaciones.

No se trata de aceptar los cambios por la moda imperante, sino en el contexto de un proceso dinámico que obliga al crecimiento de la sociedad y sus expectativas.

\section{CONCLUSION.}

En el contexto del movimiento pedagógico, la Educación Física por sus características de vivencia, acción dinámica, coherencia entre lo conceptual y lo práctico, espacio de expresión y reto individual, posibilidad creadora y diversidad de manifestaciones, se constituye en una estructura pedagógica, básica para la transformación de la escuela, no solo como una disciplina autónoma, sino porque con su objeto, tienen que interesarse las diferentes disciplinas y prácticas académicas.

Ello ubica una mayor responsabilidad pedagógica de la comunidad de la Educación Física. 